\title{
A ATIVIDADE ERVATEIRA NO PLANALTO NORTE CATARINENSE: A INDICAÇÃO GEOGRÁFICA COMO ALTERNATIVA PARA A (RE)VALORIZAÇÃO DO PRODUTO ERVA-MATE ${ }^{1}$
}

\author{
Gilcimar Adriano $\operatorname{Vogt}^{2}$ \\ Gilberto Neppel ${ }^{3}$ \\ Adriano Martinho de Souza ${ }^{4}$
}

\begin{abstract}
RESUMO
O Planalto Norte de Santa Catarina tem sua história ligada à atividade ervateira, tendo a exploração dos ervais nativos e os processos de produção regionais como elementos centrais na manutenção da notoriedade e reputação em produzir erva-mate, diferenciada e de qualidade. $\mathrm{O}$ objetivo deste artigo é analisar a cadeia produtiva da erva-mate na região do Planalto Norte de Santa Catarina a partir da interpretação estatística de variáveis relacionadas à produção e extração do produto. A maioria da erva-mate processada na região $(83 \%)$ é oriunda da extração de folhas em formações e remanescentes florestais da Floresta Ombrófila Mista, caracterizando-se como uma atividade econômica ligada à utilização sustentável da mata nativa. Portanto, o trabalho no desenvolvimento de ações para (re)valorização do produto regional, através de selos distintivos como: a Indicação Geográfica (IG), a produção e certificação orgânica ou outro selo com apelo socioambiental, apresentam grande importância no desenvolvimento socioeconômico e ambiental do território. O projeto "Ações de apoio à estruturação da Indicação Geográfica Planalto Norte Catarinense para produtos da Erva-mate" busca não apenas a formalização e a conquista do certificado de registro de uma IG, mas a participação efetiva dos atores da cadeia produtiva na sensibilização, na tomada de decisões, na viabilização de políticas públicas territoriais, na resolução de gargalos técnicos e estruturais e na construção de acordos coletivos.
\end{abstract}

Palavras-Chave: Ilex paraguariensis. Signo distintivo. Indicação Geográfica.

\footnotetext{
${ }^{1}$ Trabalho executado com financiamento do Ministério da Agricultura, Pecuária e Abastecimento - Convênio MAPA n ${ }^{\circ} 763642 / 2011$

${ }^{2}$ Possui graduação em Agronomia e mestrado em Recursos Genéticos Vegetais pela UFSC. Atualmente é pesquisador da Empresa de Pesquisa Agropecuária e Extensão Rural de Santa Catarina (Epagri). Santa Catarina. Brasil. E-mail: gilcimar@epagri.sc.gov.br

${ }^{3}$ Engenheiro Agrônomo, extensionista Regional da Epagri, coordenador/gestor do projeto IG de erva-mate. Santa Catarina. Brasil. E-mail: gilbertoneppel@epagri.sc.gov.br

${ }^{4}$ Pesquisador de Ciências Agrárias e doutorando em Recursos Genéticos Vegetais, atuando na Epagri Regional de Canoinhas. Santa Catarina. Brasil. E-mail: adriano@epagri.sc.gov.br
}

DRd - Desenvolvimento Regional em debate (ISSNe 2237-9029)

v. 6, n. 2, ed. esp., p. 64-87, jul. 2016. 


\section{ABSTRACT \\ THE MATE ACTIVITY IN NORTH PLATEAU, SANTA CATARINA STATE: THE GEOGRAPHICAL INDICATION AS AN ALTERNATIVE TO VALORIZATION OF YERBA MATE}

The North Plateau of Santa Catarina state has its history linked to mate activity, and exploitation of native herbal and regional production processes as key elements in maintaining the notorian and reputation in producing differentiated yerba mate and quality. The purpose of this article is to analyze the yerba mate production chain in North Plateau of Santa Catarina state from the statistical interpretation of variables related to the production and extraction of the product. Most of the processed yerba mate in the region (83\%) comes from the extraction of leaves in forest formations and remnants of Araucaria Forest, being characterized as an economic activity linked to the sustainable use of native forest. Therefore, the work on developing actions for (re) valorization of regional product through hallmarks as Geographical Indication (IG), organic production or other seal with socio-environmental appeal has great importance in the socio-economic and environmental development of the territory. The "structure to support actions of Geographical Indication North Plateau of Santa Catarina State for Yerba Mate products" search not only the formalization and the conquest of the certificate of registration of a IG, but the largest share of the production chain players in raising awareness, decision making, the viability of territorial public policies in solving structural bottlenecks and the construction of collective agreements.

Keywords: Ilex paraguariensis. Distinctive sign. Geographical Indications.

\section{INTRODUÇÃO}

A erva-mate (Ilex paraguariensis St. Hil.) é uma espécie arbórea que ocorre em seu estado nativo nas regiões subtropical e temperada da América do Sul (Brasil, Argentina e Paraguai), entre as latitudes $21^{\circ} \mathrm{S}$ e $30^{\circ} \mathrm{S}$ e as longitudes $48^{\circ} 30^{\prime} \mathrm{W}$ e $56^{\circ} 10^{\prime} \mathrm{W}$ (Figura 1), preferencialmente nas altitudes compreendidas entre 500 e 1.500 metros, podendo, contudo, ser encontrada em altitudes abaixo ou acima desses limites (OLIVEIRA; ROTTA, 1985; HOPPE et al., 1996). 
Figura 1 - Área de distribuição natural da erva-mate e araucária

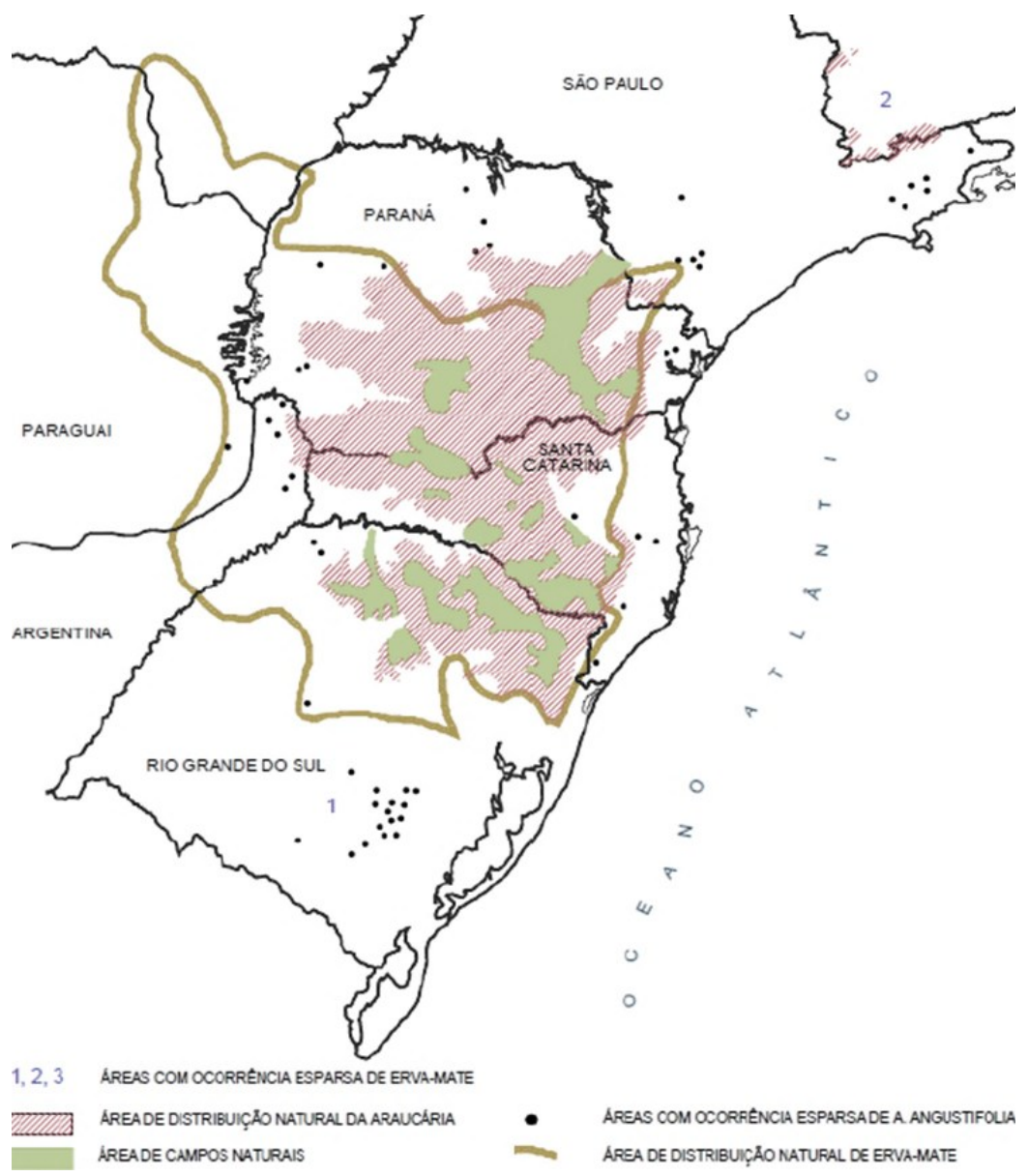

Fonte: Oliveira e Rotta (1985) e Carvalho (1994).

É endêmica e existiu na forma silvestre exclusivamente em uma região florestal do Sul da América, com concentração em uma área que corresponde hoje a Região Sul do Brasil e parte do Estado do Mato Grosso do Sul, à província de Missiones na Argentina e ao Leste do Paraguai (GERHARDT, 2013). Também segundo Gerhardt (2013), esta área de ocorrência é coincidente com bacias hidrográficas dos rios Paraná, Paraguai, Iguaçu e Uruguai e com algumas de suas sub-bacias, como as dos rios Ijuí e Turvo no Rio Grande do Sul e a do rio Negro, na divisa entre Santa Catarina e Paraná.

No Brasil, está distribuída principalmente nos Estados do Paraná, Santa Catarina e Rio Grande do Sul, embora ocorra em menor proporção (ocorrência esparsa) no Mato Grosso do Sul, São Paulo, Minas Gerais e Rio de Janeiro (CARVALHO, 1994) (Figura 1).

No Estado do Rio Grande do Sul, sua dispersão geográfica compreende principalmente a região Centro-Oeste. No Paraná, ocorre desde a região Centro-Sul e Sudoeste, ao longo dos três planaltos, até a Serra do Mar, excetuando-se o litoral. Em São Paulo, ocorre com pouca frequência, aparecendo em áreas localizadas no Sudoeste do Estado, onde são encontradas manchas de araucária. No Mato Grosso do Sul, ocorre no Sul, nos vales de Dourados, Brilhante e em outros municípios sulinos (DA CROCE; FLOSS, 1999). 
Em Santa Catarina, ocorre principalmente no planalto, desde Campo Alegre, no Planalto Norte Catarinense, até o Extremo Oeste, no município de Dionísio Cerqueira, fronteira com Missiones, na República Argentina (OLIVEIRA; ROTTA, 1985). As formações naturais se concentram ao norte do Estado (Planalto Norte do Estado) e segundo Klein (1969), a espécie é rara na mata pluvial atlântica, não sendo encontrada no litoral. Já nas matas subtropicais do Alto Uruguai, ocorre somente nos pontos de contato com os pinhais, sendo ausente na mata sem ocorrência da Araucária (KLEIN, 1972).

Dentre várias peculiaridades da erva-mate, destaca-se a adaptação tanto a pleno sol quanto ao sombreamento. De modo geral, a exploração dos ervais se dá em várias paisagens (Tabela 1), sendo os predominantes, nativos e/ou plantados, em sub-bosque (remanescentes) e/ou solteiros (monoculturais) (MARQUES, 2014).

Tabela 1 - Tipos de áreas de ervais e descrição segundo Da-Ré et al. (2012)

\begin{tabular}{cl}
\hline Tipo de ervais & \multicolumn{1}{c}{ Descrição } \\
\hline \multirow{2}{*}{ Em ser } & $\begin{array}{l}\text { Áreas com erva-mate nativa, nunca podada. Os ervais em ser não são submetidos à } \\
\text { exploração econômica, e as árvores podem atingir mais de 20 metros de altura. }\end{array}$ \\
\hline \multirow{2}{*}{ Nativas } & $\begin{array}{l}\text { Áreas remanescentes de Floresta Ombrófila Mista (FOM) com erva-mate nativa e/ou } \\
\text { plantadas (não adensadas) que são exploradas. As áreas podem ter sofrido retirada de grande } \\
\text { parte das outras espécies da FOM, restando a presença de algumas araucárias, que } \\
\text { proporcionam sombreamento aos ervais. }\end{array}$ \\
\hline Adensado & $\begin{array}{l}\text { Área nativa ou cultivada em sub-bosque que sofreu tratos culturais (raleamento ou abertura } \\
\text { de faixas nas matas ou capoeiras) para plantio de erva-mate, de modo a promover a } \\
\text { conversão daquele povoamento, originalmente mata secundária ou capoeira, num erval } \\
\text { propriamente dito. . }\end{array}$ \\
\hline Homogêneo & Erval plantado em caráter de monocultura, em pleno sol. \\
\hline Consorciado & Erval plantado em consórcio com outras culturas anuais nas entrelinhas. \\
\hline Arborizada & $\begin{array}{l}\text { Erval plantado com a introdução de árvores de espécies nativas e/ou exóticas plantadas } \\
\text { dentro das linhas de erva-mate. }\end{array}$ \\
\hline
\end{tabular}

Fonte: Elaborado pelos autores com base nas informações de Da-Ré et al. (2012)

Souza (1998a) indica que a erva-mate produzida e transformada nas regiões Norte Catarinense, Centro-sul e Sul do Paraná é um produto com histórico diferenciado (notoriedade) e que pode ser facilmente reconhecido pelos mercados consumidores. O território tem sua história ligada à atividade ervateira, tendo a exploração dos ervais nativos e os processos de produção regionais como elementos centrais na manutenção da notoriedade e reputação em produzir erva-mate diferenciada e de qualidade (CHAIMSOHN; SOUZA, 2013).

Portanto, articular os territórios rurais em torno da coordenação de atividades voltadas para (re)valorização de produtos ou serviços que reconheçam os meios tradicionais de produção, as características únicas regionais e a qualidade dos produtos e serviços de uma determinada porção dos territórios significa promover o desenvolvimento territorial e a agregação de valor ao produto regional/tradicional e proporcionar a sinergia entre os esforços das políticas públicas de geração de renda com o mercado consumidor de produtos e serviços rurais.

O objetivo deste artigo é analisar a cadeia produtiva da erva-mate na região do Planalto Norte de Santa Catarina a partir da interpretação estatística de variáveis relacionadas à produção, extração e comercialização do produto, com vistas a justificar as ações para

DRd - Desenvolvimento Regional em debate (ISSNe 2237-9029) 
efetivação da IG para produtos da erva-mate, respaldando que se trata de um produto associado à sustentabilidade, a história e a cultura do território.

\section{PROCEDIMENTOS METODOLÓGICOS}

O presente estudo caracterizou-se como sendo descritivo-estatístico, realizando uma análise quantitativa das variáveis relacionadas à produção e extração da erva-mate no Brasil, em Santa Catarina e na região do Planalto Norte Catarinense.

Foram obtidos dados de produção de erva-mate junto às estimativas da Produção Agrícola Municipal (PAM) e Produção da Extração Vegetal e da Silvicultura (PEVS) nas publicações disponíveis na homepage do Instituto Brasileiro de Geografia e Estatística (IBGE, 2016).

Foram analisados os dados da produção de erva-mate expressa em tonelada de folha verde por hectare, analisada no período de 1971 a 2014. Cabe salientar que os dados da PAM até 1987 e da PEVS até o ano de 2001 eram expressos em toneladas de erva-mate cancheada, foram convertidos pelos autores para toneladas de folha verde utilizando o conversor 2,5/1, conforme sugerido por Souza (1998b) e IBAMA (1992).

Neste artigo é também apresentada a metodologia adotada pelas instituições no Planalto Norte Catarinense em um contexto histórico que levou o território a exercitar uma proposta de IG para a antiga Região tradicional Paraná/Santa Catarina para produtos da ervamate.

Para análise dos dados foram utilizadas ferramentas de estatística descritiva com intuito de caracterizar as variáveis de produção de erva-mate em cada tipo de dados (PEVS e PAM) e porcentagem de erva-mate produzida em cada tipo de dado. Para sistematização e exploração dos dados foi utilizado o software Microsoft Excel, realizando-se análise exploratória de dados através de estatísticas descritivas, apresentando os dados em tabelas e gráficos.

Para melhor discutir os dados e informações coletadas foram utilizadas metodologias qualitativas complementares como observação direta e revisão bibliográfica, a fim de conhecer as diferentes opiniões e fatos e auxiliar na leitura e interpretação das informações quantitativas.

\section{ANÁLISE DA PRODUÇÃO E EXTRAÇÃO DA ERVA-MATE}

Em 2014, a produção mundial de erva-mate foi de 1.809 .579 toneladas de erva-mate folha verde. O Brasil com 935.501 toneladas (51,7\% da produção mundial), a Argentina com 782.078 toneladas (INYM, 2016) (43,2\% da produção mundial) e o Paraguai com 92.000 toneladas (MAG, 2016) (5,1\% da produção mundial).

No Brasil, os dados estatísticos da matéria prima erva-mate informados pelo IBGE estão separados com base no sistema de produção, podendo ser procedente da Produção 
Agrícola Municipal (PAM) ou da Produção da Extração Vegetal e da Silvicultura (PEVS). Pelo PAM, em 2014 foram produzidas 602.484 toneladas de erva-mate folha verde e pela PEVS, a extração dos ervais nativos foi de 333.017 toneladas de folha verde (Tabela 2).

Tabela 2 - Produção brasileira de erva-mate folha verde total (PAM+PEVS), cultivada (PAM) e proveniente do extrativismo (PEVS) entre os anos de 1971 e 2014

\begin{tabular}{|c|c|c|c|c|c|}
\hline \multirow{2}{*}{ Ano } & \multicolumn{5}{|c|}{ Brasil } \\
\hline & PAM & PEVS & \%РAM & $\%$ PEVS & Total \\
\hline 1971 & 0 & 264.743 & 0,0 & 100,0 & 264.743 \\
\hline 1972 & 0 & 261.218 & 0,0 & 100,0 & 261.218 \\
\hline 1973 & 0 & 260.718 & 0,0 & 100,0 & 260.718 \\
\hline 1974 & 0 & 215.340 & 0,0 & 100,0 & 215.340 \\
\hline 1975 & 0 & 236.590 & 0,0 & 100,0 & 236.590 \\
\hline 1976 & 0 & 216.345 & 0,0 & 100,0 & 216.345 \\
\hline 1977 & 0 & 236.738 & 0,0 & 100,0 & 236.738 \\
\hline 1978 & 32.143 & 213.703 & 13,1 & 86,9 & 245.845 \\
\hline 1979 & 39.035 & 210.088 & 15,7 & 84,3 & 249.123 \\
\hline 1980 & 71.918 & 262.510 & 21,5 & 78,5 & 334.428 \\
\hline 1981 & 46.470 & 254.695 & 15,4 & 84,6 & 301.165 \\
\hline 1982 & 45.265 & 247.188 & 15,5 & 84,5 & 292.453 \\
\hline 1985 & 75.113 & 270.330 & 21,7 & 78,3 & 345.443 \\
\hline 1986 & 99.655 & 304.770 & 24,6 & 75,4 & 404.425 \\
\hline 1987 & 159.168 & 349.978 & 31,3 & 68,7 & 509.145 \\
\hline 1988 & 85.480 & 362.660 & 19,1 & 80,9 & 448.140 \\
\hline 1989 & 90.873 & 364.123 & 20,0 & 80,0 & 454.995 \\
\hline 1990 & 147.073 & 377.058 & 28,1 & 71,9 & 524.130 \\
\hline 1991 & 166.430 & 523.318 & 24,1 & 75,9 & 689.748 \\
\hline 1992 & 145.973 & 520.745 & 21,9 & 78,1 & 666.718 \\
\hline 1993 & 227.338 & 609.225 & 27,2 & 72,8 & 836.563 \\
\hline 1994 & 222.378 & 519.950 & 30,0 & 70,0 & 742.328 \\
\hline 1995 & 247.214 & 510.163 & 32,6 & 67,4 & 757.377 \\
\hline 1996 & 214.576 & 422.578 & 33,7 & 66,3 & 637.154 \\
\hline 1997 & 307.327 & 473.673 & 39,4 & 60,6 & 781.000 \\
\hline 1998 & 424.433 & 458.760 & 48,1 & 51,9 & 883.193 \\
\hline 1999 & 462.665 & 442.305 & 51,1 & 48,9 & 904.970 \\
\hline 2000 & 522.019 & 436.203 & 54,5 & 45,5 & 958.222 \\
\hline 2001 & 645.965 & 455.443 & 58,6 & 41,4 & 1.101 .408 \\
\hline 2002 & 513.526 & 229.701 & 69,1 & 30,9 & 743.227 \\
\hline 2003 & 501.702 & 220.189 & 69,5 & 30,5 & 721.891 \\
\hline 2004 & 403.281 & 246.837 & 62,0 & 38,0 & 650.118 \\
\hline 2005 & 429.730 & 238.869 & 64,3 & 35,7 & 668.599 \\
\hline 2006 & 434.483 & 233.360 & 65,1 & 34,9 & 667.843 \\
\hline 2007 & 438.747 & 225.957 & 66,0 & 34,0 & 664.704 \\
\hline 2008 & 434.727 & 219.773 & 66,4 & 33,6 & 654.500 \\
\hline 2009 & 443.126 & 218.102 & 67,0 & 33,0 & 661.228 \\
\hline 2010 & 430.305 & 227.462 & 65,4 & 34,6 & 657.767 \\
\hline 2011 & 443.635 & 229.681 & 65,9 & 34,1 & 673.316 \\
\hline 2012 & 513.256 & 252.700 & 67,0 & 33,0 & 765.956 \\
\hline 2013 & 515.451 & 344.411 & 59,9 & 40,1 & 859.862 \\
\hline 2014 & 561.617 & 373.884 & 60,0 & 40,0 & 935.501 \\
\hline
\end{tabular}

Fonte: Resultados da pesquisa elaborado pelos autores com base nos dados obtidos do IBGE (2016)

DRd - Desenvolvimento Regional em debate (ISSNe 2237-9029)

v. 6, n. 2, ed. esp., p. 64-87, jul. 2016. 
Até 1998, a maior parte do mate produzido no Brasil provinha da exploração dos ervais nativos (PEVS). Entretanto, principalmente devido à queda de sua produção, pela exploração contínua e avanço da agricultura, houve um aumento na demanda do produto, tornando a prática do plantio em monocultivo mais comum. A erva-mate vinda de plantios começa a ter expressão a partir de meados da década de 1980, no Rio Grande do Sul, no Paraná e no Oeste de Santa Catarina, estando notificadas a partir de 1978 (Tabela 2), conforme também relatado por Souza (1998b). O mesmo autor relata que entre anos 1993 e 1995, a produção derivada de ervais plantados era de $29,8 \%$ e que houve a tendência de aumento da participação dos ervais plantados devido aumentos nas áreas plantadas, ganhos de produtividade mais intensos nas áreas plantadas por meio da melhoria do manejo e intensos de trabalhos de pesquisa e extensão rural nos três Estados do Sul.

A partir de 1970, a atividade ervateira sofreu muitas mudanças: a erradicação de ervais nativos em algumas regiões para dar lugar a reflorestamentos e a culturas anuais principalmente a soja, a diminuição das exportações, o aumento do consumo interno, a formação de uma nova agroindústria, o abandono dos processos tradicionais de transformação na maior parte das regiões, o início de plantios de erva-mate e o paulatino aumento da participação destes ervais plantados na produção. Além disso, houve a flexibilização das regulamentações de períodos de colheita e de intervalos entre as colheitas, e os produtos regionais diferenciados tenderam a dar lugar a um tipo de produto padronizado.

Gerhardt (2013) relata que apesar do empenho dos governos municipais e provinciais para a conservação dos ervais, na prática, as estratégias se mostraram incapazes de impedir a exploração descontrolada dos bens florestais. O mesmo autor relata que uma parte dos ervais nativos remanescentes existiu até as décadas de 1960 e 1970, quando houve uma onda de modernização agropecuária marcada pela industrialização e pela introdução da soja, desencadeando a derrubada de remanescentes florestais e de ervais até então conservados.

Souza (1998b) relata que nas últimas décadas (especialmente 1980 e 1990) a atividade ervateira passou por profundas mudanças, onde uma nova agroindústria ervateira se constituiu, tendo empregados permanentes e operação contínua, necessitando assim fornecimento contínuo de matéria prima e escala de produção para fazer frente aos investimentos e custos operacionais, o que era proporcionado mais facilmente pelos ervais plantados.

A partir de 1978, a produção brasileira de erva-mate cultivada (PAM) mostra tendência ascendente até 2001 (Figura 2), ocorrendo ápice da produção com 645.965 toneladas de folha verde. Entre 2012 e 2014 houve nova ascendente motivado pelo aumento do preço no período, o que motivou o manejo de ervais, especialmente os antigos e/ou abandonados. Nas estimativas do PAM, o incremento na produção de erva-mate entre 2011 e 2014 foi de $31 \%$. 
Figura 2 - Produção brasileira de erva-mate folha verde total (PAM+PEVS), cultivada (PAM) e proveniente do extrativismo (PEVS) entre os anos de 1971 e 2014

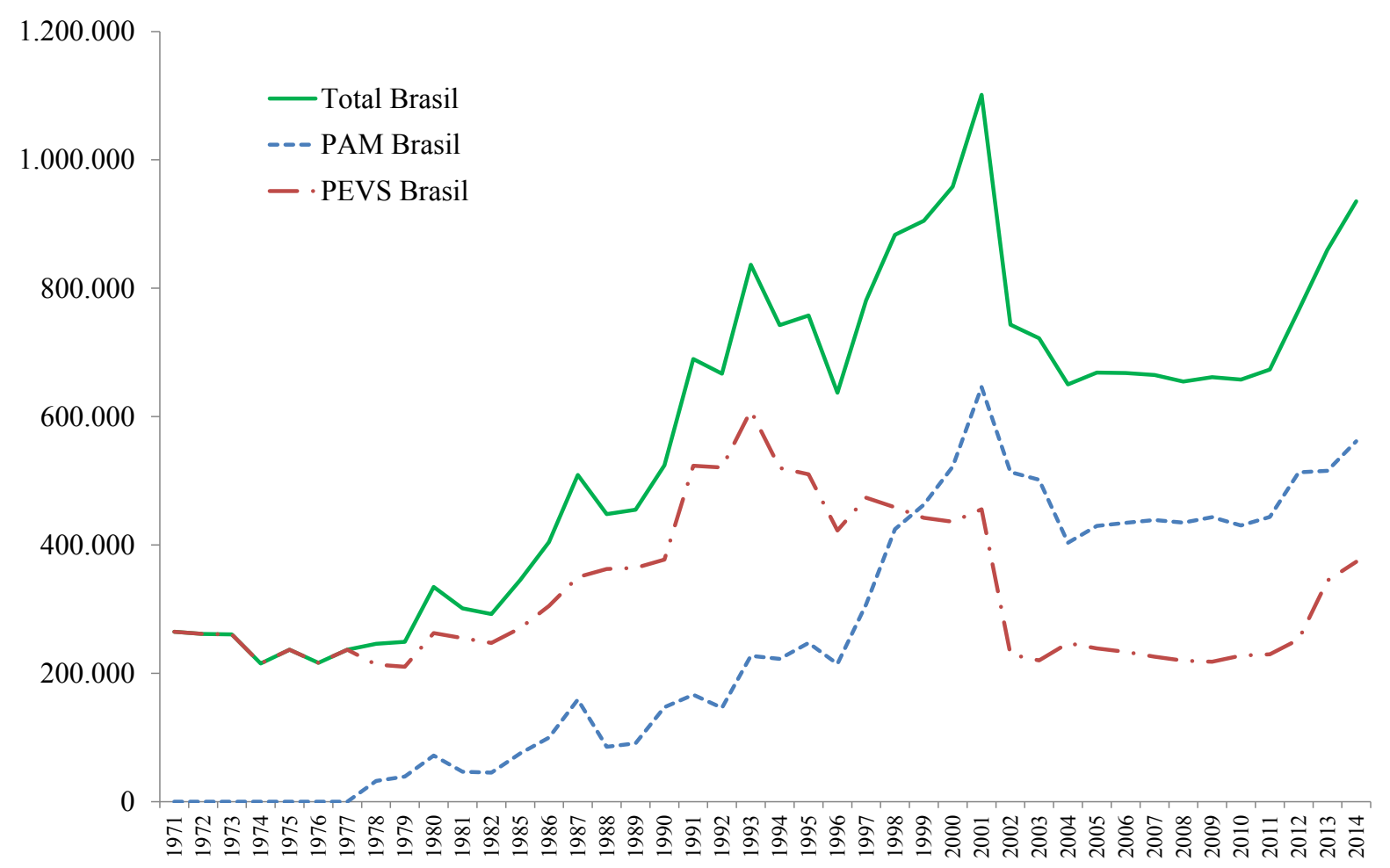

Fonte: Resultados da pesquisa elaborado pelos autores com base nos dados obtidos do IBGE (2016)

Os dados de erva-mate oriunda da extração vegetal (PEVS) apresentaram redução em 2002 (em torno de 50\%) em relação ao ano anterior e mantiveram-se constantes até 2013, quando apresentaram incremento de $63 \%$ entre 2011 e 2014, também devido ao atraente preço e a exploração de remanescentes florestais onde anteriormente não havia exploração da atividade ervateira frequente. Nota-se que a produção advinda da extração vegetal (PEVS) era maior do que a produção de erva-mate cultivada (PAM) até o ano 1998 e atualmente representa apenas $40 \%$ da produção total nacional (Tabela 1 ).

O Estado de Santa Catarina foi responsável por 13,2\% da produção nacional de ervamate em 2014, ou seja, produziu 123.810 toneladas de erva-mate folha verde. As estimativas de produção de PEVS foram superiores a PAM em 2014, sendo produzidos 66.158 (PEVS) e 57.652 (PAM) toneladas de erva-mate folha verde (Tabela 3).

A produção catarinense está concentrada nas regiões Planalto Norte (Canoinhas + São Bento do Sul), Planalto serrano (Campos de Lages), Vale do Itajaí (Rio do Sul) Meio Oeste (Curitibanos + Joaçaba), Oeste (Concórdia + Xanxerê + Chapecó) e Extremo Oeste (São Miguel do Oeste). Destaca-se o contraste entre a produção PAM nas regiões Oeste e Meio Oeste e a produção de PEVS no Planalto Norte (Figura 3). 
Figura 3 - Cartograma de distribuição por microrregião do IBGE da produção de erva-mate folha verde no Estado de Santa Catarina Produção, (a) cultivada (PAM) e (b) proveniente do extrativismo (PEVS) no ano de 2012

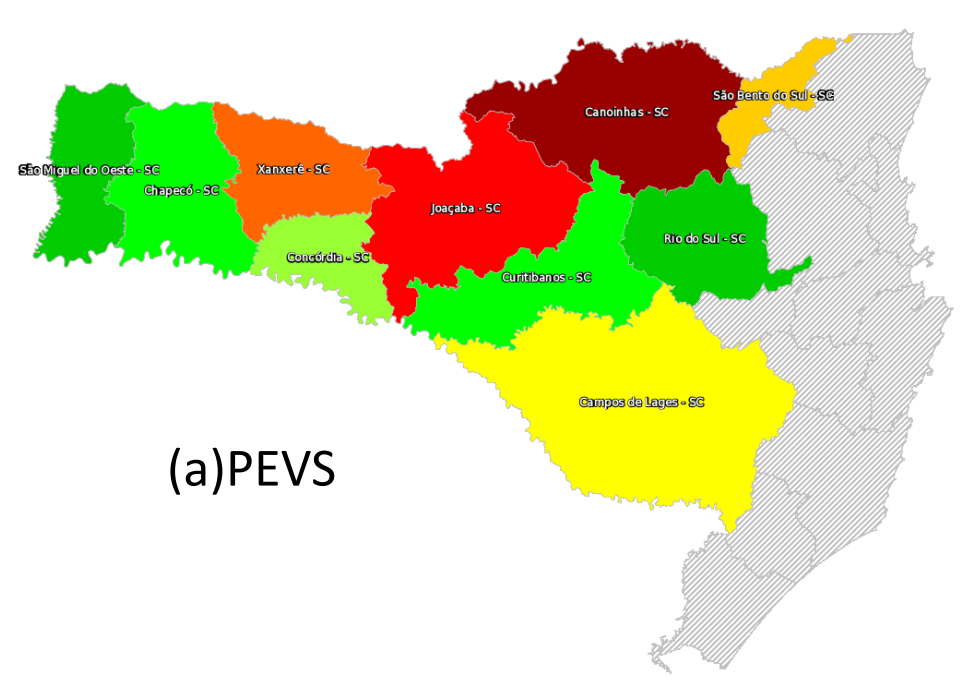

\begin{tabular}{|c|c|c|}
\hline \multicolumn{3}{|c|}{ Tipo de produto extrativo $=1.4-$ Erva-mate } \\
\hline \multicolumn{3}{|c|}{ Ano $=2012$} \\
\hline Nome & Valor & Cor \\
\hline Araranguá - SC & $\ldots$ & //I/// \\
\hline Blumenau - SC & ... & I/II/I \\
\hline Campos de Lages - SC & 2.023 & \\
\hline Canoinhas - SC & 19.200 & \\
\hline Chapecó - SC & 1.106 & \\
\hline Concórdia - SC & 1.111 & \\
\hline Criciúma - SC & - & //I/// \\
\hline Curitibanos - SC & 442 & \\
\hline Florianópolis - SC & - & IIII/I \\
\hline Itajaí - SC & - & IIIII/ \\
\hline Ituporanga - SC & - & ////// \\
\hline Joaçaba - SC & 5.472 & \\
\hline Joinville - SC & ... & I/I/I/I \\
\hline Rio do Sul - SC & 164 & \\
\hline São Bento do Sul - SC & 2.754 & \\
\hline São Miguel do Oeste - SC & 394 & \\
\hline Tabuleiro - SC & - & //I/// \\
\hline Tijucas - SC & - & /IIIII \\
\hline Tubarão - SC & - & IIIIII \\
\hline Xanxerê - SC & 3.439 & \\
\hline
\end{tabular}

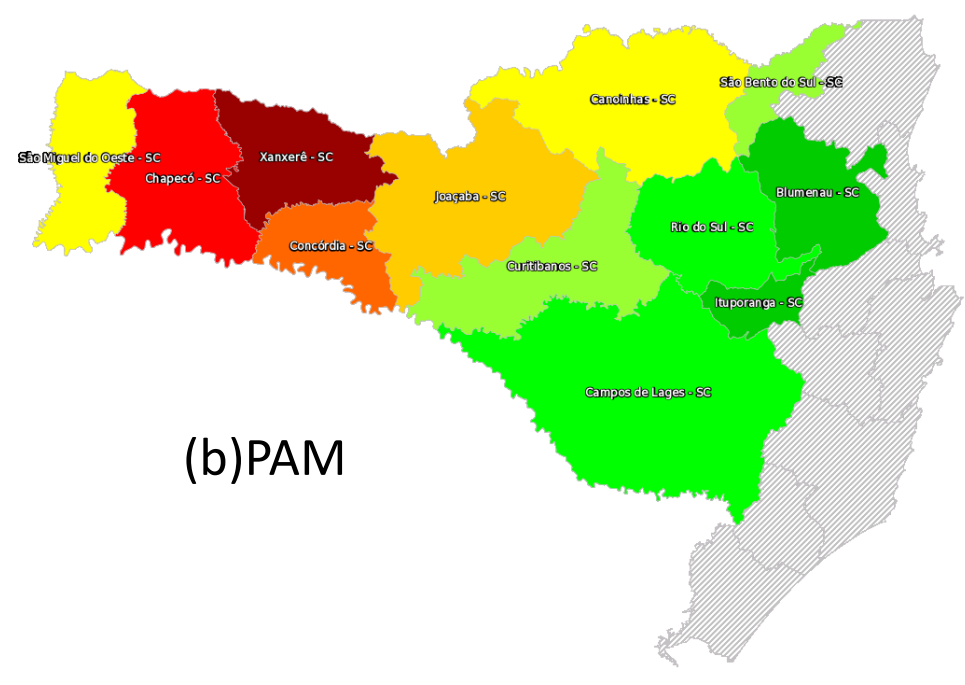

\begin{tabular}{|c|c|c|}
\hline \multicolumn{3}{|c|}{ Lavoura permanente = Erva-mate (folha verde) } \\
\hline \multicolumn{3}{|c|}{ Ano $=2012$} \\
\hline Nome & Valor & Cor \\
\hline Araranguá - SC & - & ////// \\
\hline Blumenau - SC & 30 & \\
\hline Campos de Lages - SC & 85 & \\
\hline Canoinhas - SC & 3.424 & \\
\hline Chapecó - SC & 20.485 & \\
\hline Concórdia - SC & 9.333 & \\
\hline Criciúma - SC & - & //I/// \\
\hline Curitibanos - SC & 246 & \\
\hline Florianópolis - SC & - & //I/I/ \\
\hline Itajaí - SC & - & ////// \\
\hline Ituporanga - SC & 40 & \\
\hline Joaçaba - sc & 7.610 & \\
\hline Joinville - SC & - & IIIII/ \\
\hline Rio do Sul - SC & 140 & \\
\hline São Bento do Sul - SC & 497 & \\
\hline São Miguel do Oeste - SC & 903 & \\
\hline Tabuleiro - SC & - & //I/// \\
\hline Tijucas - SC & - & //II// \\
\hline Tubarão - SC & - & IIIIII \\
\hline Xanxerê - SC & 26.271 & \\
\hline
\end{tabular}

Fonte: Resultados da pesquisa adaptado pelos autores do sistema SIDRA (IBGE, 2016)

A produção da PEVS no Estado foi ascendente até 1993, ano em que ocorreu redução de 37,5\% (Figura 4). A partir de 1995 tem ocorrido decréscimo da produção, voltando a aumentar em 2013 e 2014, alavancadas pela valorização do preço da erva-mate aos produtores. A produção de PAM iniciou também em 1978, com grande aumento de produção nos anos de 1980 e 1981, queda entre 1988 e 1990, e retomada a partir de 1991. 
Tabela 3 - Produção catarinense de erva-mate folha verde total (PAM+PEVS), cultivada (PAM) e proveniente do extrativismo (PEVS) entre os anos de 1971 e 2014

\begin{tabular}{|c|c|c|c|c|c|}
\hline \multirow{2}{*}{ Ano } & \multicolumn{5}{|c|}{ Santa Catarina } \\
\hline & PAM & PEVS & \%PAM & $\%$ PEVS & Total \\
\hline 1971 & 0 & 61.075 & 0,0 & 100,0 & 61.075 \\
\hline 1972 & 0 & 63.240 & 0,0 & 100,0 & 63.240 \\
\hline 1973 & 0 & 61.665 & 0,0 & 100,0 & 61.665 \\
\hline 1974 & 0 & 71.220 & 0,0 & 100,0 & 71.220 \\
\hline 1975 & 0 & 81.773 & 0,0 & 100,0 & 81.773 \\
\hline 1976 & 0 & 69.280 & 0,0 & 100,0 & 69.280 \\
\hline 1977 & 0 & 77.868 & 0,0 & 100,0 & 77.868 \\
\hline 1978 & 168 & 68.303 & 0,2 & 99,8 & 68.470 \\
\hline 1979 & 283 & 62.055 & 0,5 & 99,5 & 62.338 \\
\hline 1980 & 7.618 & 75.868 & 9,1 & 90,9 & 83.485 \\
\hline 1981 & 8.643 & 84.475 & 9,3 & 90,7 & 93.118 \\
\hline 1982 & 5.383 & 86.048 & 5,9 & 94,1 & 91.430 \\
\hline 1985 & 9.165 & 95.125 & 8,8 & 91,2 & 104.290 \\
\hline 1986 & 10.235 & 108.635 & 8,6 & 91,4 & 118.870 \\
\hline 1987 & 13.013 & 115.243 & 10,1 & 89,9 & 128.255 \\
\hline 1988 & 4.593 & 128.908 & 3,4 & 96,6 & 133.500 \\
\hline 1989 & 3.555 & 129.563 & 2,7 & 97,3 & 133.118 \\
\hline 1990 & 4.995 & 124.898 & 3,8 & 96,2 & 129.893 \\
\hline 1991 & 34.623 & 274.310 & 11,2 & 88,8 & 308.933 \\
\hline 1992 & 16.515 & 279.163 & 5,6 & 94,4 & 295.678 \\
\hline 1993 & 23.103 & 303.008 & 7,1 & 92,9 & 326.110 \\
\hline 1994 & 27.930 & 189.643 & 12,8 & 87,2 & 217.573 \\
\hline 1995 & 39.371 & 198.375 & 16,6 & 83,4 & 237.746 \\
\hline 1996 & 51.615 & 133.670 & 27,9 & 72,1 & 185.285 \\
\hline 1997 & 46.017 & 133.813 & 25,6 & 74,4 & 179.830 \\
\hline 1998 & 53.932 & 128.508 & 29,6 & 70,4 & 182.440 \\
\hline 1999 & 71.312 & 112.643 & 38,8 & 61,2 & 183.955 \\
\hline 2000 & 63.203 & 99.918 & 38,7 & 61,3 & 163.121 \\
\hline 2001 & 48.834 & 83.765 & 36,8 & 63,2 & 132.599 \\
\hline 2002 & 45.600 & 71.642 & 38,9 & 61,1 & 117.242 \\
\hline 2003 & 52.474 & 68.393 & 43,4 & 56,6 & 120.867 \\
\hline 2004 & 37.577 & 66.078 & 36,3 & 63,7 & 103.655 \\
\hline 2005 & 37.629 & 61.635 & 37,9 & 62,1 & 99.264 \\
\hline 2006 & 35.292 & 41.833 & 45,8 & 54,2 & 77.125 \\
\hline 2007 & 37.909 & 40.559 & 48,3 & 51,7 & 78.468 \\
\hline 2008 & 41.890 & 39.637 & 51,4 & 48,6 & 81.527 \\
\hline 2009 & 46.254 & 36.493 & 55,9 & 44,1 & 82.747 \\
\hline 2010 & 43.266 & 36.274 & 54,4 & 45,6 & 79.540 \\
\hline 2011 & 45.614 & 36.117 & 55,8 & 44,2 & 81.731 \\
\hline 2012 & 69.064 & 36.105 & 65,7 & 34,3 & 105.169 \\
\hline 2013 & 50.740 & 69.683 & 42,1 & 57,9 & 120.423 \\
\hline 2014 & 57.652 & 66.158 & 46,6 & 53,4 & 123.810 \\
\hline
\end{tabular}

Fonte: Resultados da pesquisa elaborado pelos autores com base nos dados obtidos do IBGE (2016) 
Figura 4 - Produção do Estado de Santa Catarina de erva-mate folha verde total (PAM+PEVS), cultivada (PAM) e proveniente do extrativismo (PEVS) entre os anos de 1971 e 2014

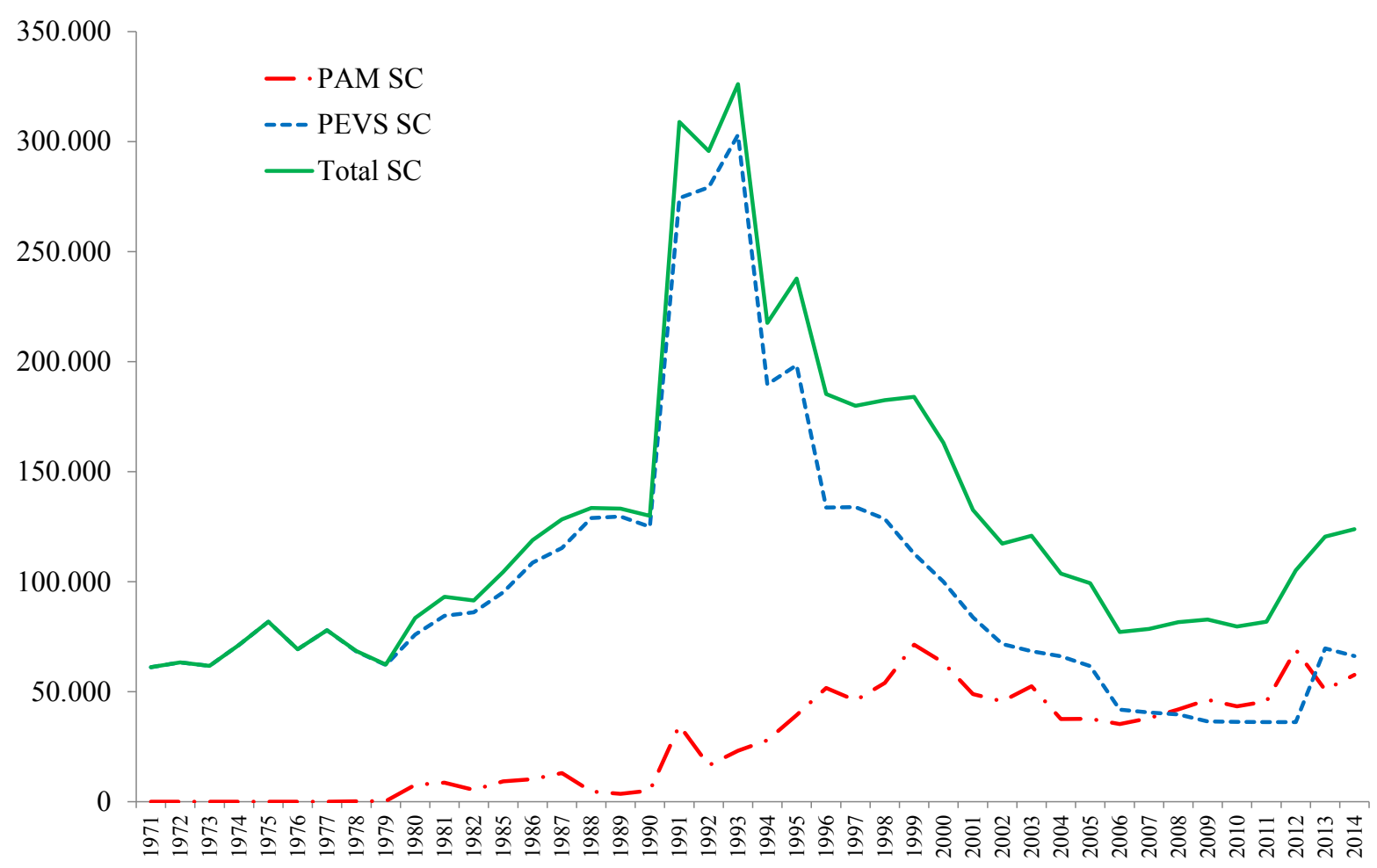

Fonte: Resultados da pesquisa elaborado pelos autores com base nos dados obtidos do IBGE (2016)

A região do Planalto Norte de Santa Catarina foi responsável por 49,3\% da produção estadual de erva-mate folha verde em 2014, produzindo 61.107 toneladas. Historicamente, as estimativas regionais de produção de PEVS sempre foram muito superiores a PAM. Em 2014, foram produzidos 50.987 (PEVS) e 10.120 (PAM) toneladas de erva-mate folha verde (Tabela 4), cenário contrastante em relação a produção nacional e a produção estadual. 
Tabela 4 - Produção de erva-mate folha verde total (PAM+PEVS), cultivada (PAM) e proveniente do extrativismo (PEVS) da região do Planalto Norte de Santa Catarina entre os anos de 1971 e 2014

\begin{tabular}{|c|c|c|c|c|c|}
\hline \multirow{2}{*}{ Ano } & \multicolumn{5}{|c|}{ Planalto Norte (CAN+SBS) } \\
\hline & PAM & PEVS & \%PAM & $\%$ PEVS & Total \\
\hline 1971 & 0 & 39.198 & 0,0 & 100,0 & 39.198 \\
\hline 1972 & 0 & 38.798 & 0,0 & 100,0 & 38.798 \\
\hline 1973 & 0 & 39.195 & 0,0 & 100,0 & 39.195 \\
\hline 1974 & 0 & 43.670 & 0,0 & 100,0 & 43.670 \\
\hline 1975 & 0 & 54.248 & 0,0 & 100,0 & 54.248 \\
\hline 1976 & 0 & 41.915 & 0,0 & 100,0 & 41.915 \\
\hline 1977 & 0 & 48.545 & 0,0 & 100,0 & 48.545 \\
\hline 1978 & 0 & 33.295 & 0,0 & 100,0 & 33.295 \\
\hline 1979 & 0 & 25.248 & 0,0 & 100,0 & 25.248 \\
\hline 1980 & 0 & 26.655 & 0,0 & 100,0 & 26.655 \\
\hline 1981 & 0 & 22.243 & 0,0 & 100,0 & 22.243 \\
\hline 1982 & 0 & 20.935 & 0,0 & 100,0 & 20.935 \\
\hline 1985 & 0 & 24.548 & 0,0 & 100,0 & 24.548 \\
\hline 1986 & 218 & 26.883 & 0,8 & 99,2 & 27.100 \\
\hline 1987 & 218 & 28.518 & 0,8 & 99,2 & 28.735 \\
\hline 1988 & 31 & 31.245 & 0,1 & 99,9 & 31.276 \\
\hline 1989 & 2 & 32.503 & 0,0 & 100,0 & 32.505 \\
\hline 1990 & 95 & 35.175 & 0,3 & 99,7 & 35.270 \\
\hline 1991 & 80 & 183.813 & 0,0 & 100,0 & 183.893 \\
\hline 1992 & 80 & 189.053 & 0,0 & 100,0 & 189.133 \\
\hline 1993 & 84 & 180.785 & 0,0 & 100,0 & 180.869 \\
\hline 1994 & 84 & 62.838 & 0,1 & 99,9 & 62.922 \\
\hline 1995 & 1.628 & 67.635 & 2,3 & 97,7 & 69.263 \\
\hline 1996 & 1.986 & 59.900 & 3,2 & 96,8 & 61.886 \\
\hline 1997 & 2.177 & 63.473 & 3,3 & 96,7 & 65.650 \\
\hline 1998 & 2.221 & 62.163 & 3,4 & 96,6 & 64.384 \\
\hline 1999 & 2.188 & 58.538 & 3,6 & 96,4 & 60.726 \\
\hline 2000 & 2.728 & 55.045 & 4,7 & 95,3 & $\mathbf{5 7 . 7 7 3}$ \\
\hline 2001 & 2.757 & 56.628 & 4,6 & 95,4 & 59.385 \\
\hline 2002 & 1.997 & 53.053 & 3,6 & 96,4 & 55.050 \\
\hline 2003 & 2.617 & 53.043 & 4,7 & 95,3 & 55.660 \\
\hline 2004 & 2.638 & 46.823 & 5,3 & 94,7 & 49.461 \\
\hline 2005 & 2.819 & 41.958 & 6,3 & 93,7 & 44.777 \\
\hline 2006 & 1.997 & 23.104 & 8,0 & 92,0 & 25.101 \\
\hline 2007 & 2.595 & 22.628 & 10,3 & 89,7 & 25.223 \\
\hline 2008 & 3.467 & 21.006 & 14,2 & 85,8 & 24.473 \\
\hline 2009 & 2.886 & 20.236 & 12,5 & 87,5 & 23.122 \\
\hline 2010 & 3.947 & 21.809 & 15,3 & 84,7 & 25.756 \\
\hline 2011 & 4.187 & 21.774 & 16,1 & 83,9 & 25.961 \\
\hline 2012 & 3.921 & 21.954 & 15,2 & 84,8 & 25.875 \\
\hline 2013 & 13.493 & 55.000 & 19,7 & 80,3 & 68.493 \\
\hline 2014 & 10.120 & 50.987 & 16,6 & 83,4 & 61.107 \\
\hline
\end{tabular}

Fonte: Resultados da pesquisa elaborado pelos autores com base nos dados obtidos do IBGE (2016) 
Figura 5 - Produção da região do Planalto Norte de Santa Catarina de erva-mate folha verde total (PAM+PEVS), cultivada (PAM) e proveniente do extrativismo (PEVS) entre os anos de 1971 e 2014

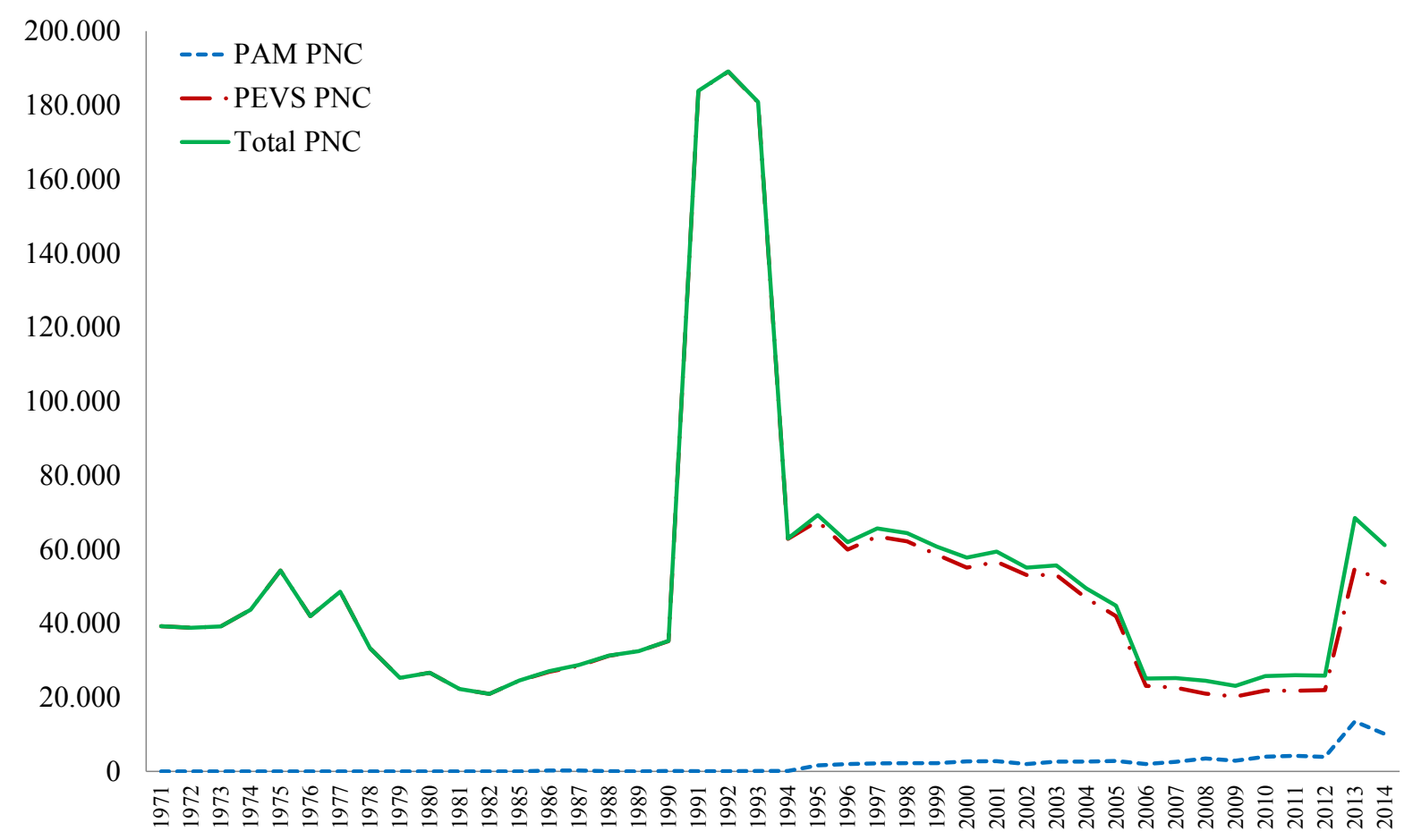

Fonte: Resultados da pesquisa elaborado pelos autores com base nos dados obtidos do IBGE (2016)

A produção de erva-mate proveniente da extração de erva-mate nativa corresponde a $83,4 \%$ da produção da região, ou seja, a maioria da erva-mate produzida na região do Planalto Norte de Santa Catarina é oriunda da extração de ervais nativos. Dados que reforçam que a erva-mate processada na região é oriunda da extração de folhas em formações e remanescentes florestais da Floresta Ombrófila Mista, caracterizando-se como uma atividade econômica ligada à utilização sustentável da mata nativa (SOUZA, 1998). Gerhardt (2013) ressalta que apesar da exploração florestal intensa ocorrida na região de ocorrência endêmica de erva-mate, diversos ervais nativos foram conservados, especialmente no Paraná e em Santa Catarina.

Entretanto, a competitividade da aglomeração de empresas ervateiras deste território tem diminuído, tendo em vista, por um lado, os maiores custos de produção da erva-mate em ambientes manejados (ervais nativos) em comparação aos menores custos de produção de outras regiões ervateiras com ervais em plantios homogêneos (SOUZA, 2009), especialmente em virtude da menor produtividade e reduzida densidade de plantas (SIGNOR et al. 2015).

A ligação que o Planalto Norte Catarinense mantém com a atividade ervateira, que legitimam os esforços para estudos e ações para (re)valorização da cadeia produtiva é muito forte se considerarmos que é uma atividade comercial que ocorre há mais de 150 anos na região, que mais de 20 empresas com marcas próprias (a mais antiga datada do ano de 1918 e dentre estas, as Cooperativas de Mate de Canoinhas e de Campo Alegre, datadas de 1932 e 1938, respectivamente) produzem diversos tipos de produtos (de chimarrão a chás verdes e 
tostados) para consumo interno e para exportação e que a produção, em quase sua totalidade, é oriunda de "ervais nativos".

Souza (1998a) e Gerhardt (2013) ressaltam que a atividade ervateira ocupa uma posição de destaque na produção extrativa vegetal, que na região a atividade ervateira com fins mercantis, em especial a exportação, está presente desde meados do século XIX, que apresenta grande importância no desenvolvimento socioeconômico e ambiental do território, e que o Planalto Norte foi a principal região catarinense de produção e transformação de ervamate desde o terço final do século XIX até meados anos 1980.

Portanto, o trabalho no desenvolvimento de ações para (re)valorização do produto regional através de selos distintivos como a Indicação Geográfica, a produção orgânica ou outro selo com apelo socioambiental (conservação das florestas, produzidos pela agricultura familiar, etc.) apresenta grande importância no desenvolvimento socioeconômico e ambiental do território, revitalizando e mantendo a história passada viva.

Portanto, articular os territórios rurais em torno da coordenação de atividades voltadas para (re)valorização de produtos ou serviços que reconheçam os meios tradicionais de produção, as características únicas regionais e a qualidade dos produtos e serviços de uma determinada porção dos territórios significa promover o desenvolvimento territorial e a agregação de valor ao produto regional/tradicional.

Atualmente, as cadeias produtivas estão inseridas em um ambiente macroeconômico onde as mudanças e a competição na indústria exigem posturas cada vez mais dinâmicas e estratégicas e a atividade ervateira brasileira não é uma exceção a esta realidade. Constantemente são necessárias melhorias melhoria em diversos aspectos, tais como tecnologia industrial, planejamento empresarial e de alternativas de mercado, bem como de normativos legais apropriados e demandas tecnológicas.

E como alternativas de mercado, sugerem-se ações e investimentos na constituição e formação de grupos com interesses comuns. É a partir desse exercício que se constrói um instrumento de trabalho que futuramente poderá ser utilizado para os ajustes nos rumos da missão, das metas e das estratégias de ação a serem ainda percorridas.

Uma das formas de valorização econômica e de proteção do conhecimento e dos processos de produção e transformação locais pode ser por meio da Indicação Geográfica (IG), com a qual o Sindicato das Indústrias do Mate do Estado de Santa Catarina (SINDIMATE), a Associação Ervateira Planalto Norte Catarinense e a EPAGRI assumiram a organização e a responsabilidade na animação e desenvolvimento de um projeto para promoção de ações de apoio à estruturação e constituição da IG para produtos da erva-mate e o qual será brevemente descrito abaixo. 


\section{AÇÕES E ESTRATÉGIAS PARA CONSTITUIÇÃO DE INDICAÇÃO GEOGRÁFICA (IG) PARA PRODUTOS DA ERVA-MATE}

Os processos de reconhecimento e registro de uma IG para produtos agropecuários é uma estratégia importante na valorização e fortalecimento de algumas cadeias produtivas, contribuindo inclusive para o desenvolvimento territorial (VALENTE et al. 2012).

O potencial de uma IG para produtos da erva-mate é claro, apresentando o produto notoriedade, reputação e diferencial, tornando indissociável a ligação dos produtos derivados da erva-mate com sua origem geográfica (SOUZA, 2010).

Apesar de que Lopes, 2011, em diagnósticos preliminares ter verificado que o signo distintivo de uma IG não é conhecido no território Planalto Norte, o mercado consumidor faz ligação entre a erva-mate e o território por meio da história produtiva, da paisagem típica regional e da qualidade e seus diferencias produtivos.

Os trabalhos para a efetivação da IG para produtos da erva-mate descortinam potenciais para a valorização de um produto associado à sustentabilidade, da história e da cultura do território, constituindo-se como ferramentas de marketing e de valorização do território e dos seus produtos, promovendo o desenvolvimento e a inovação tecnológica, melhorando a qualidade dos produtos e proporcionando diferencial de competitividade junto aos mercados consumidores (SOUZA et al. 2013).

O processo promoverá maior organização e fortalecimento da cadeia produtiva, fortalecimento ao apoio técnico e científico, mobilização para as ações de adequação aos novos cenários e as novas exigências dos consumidores, antecipando às mudanças do mercado, além de mobilizar as forças para a manutenção da atividade produtiva no território e reconstrução de sua identidade (VOGT et al. 2014) (Figura 6). 
Figura 6 - Possíveis benefícios econômicos, sociais e ambientais proporcionados pela construção conjunta de signo distintivo IG para produtos da cadeia produtiva da erva-mate nas regiões Planalto Norte de Santa Catarina

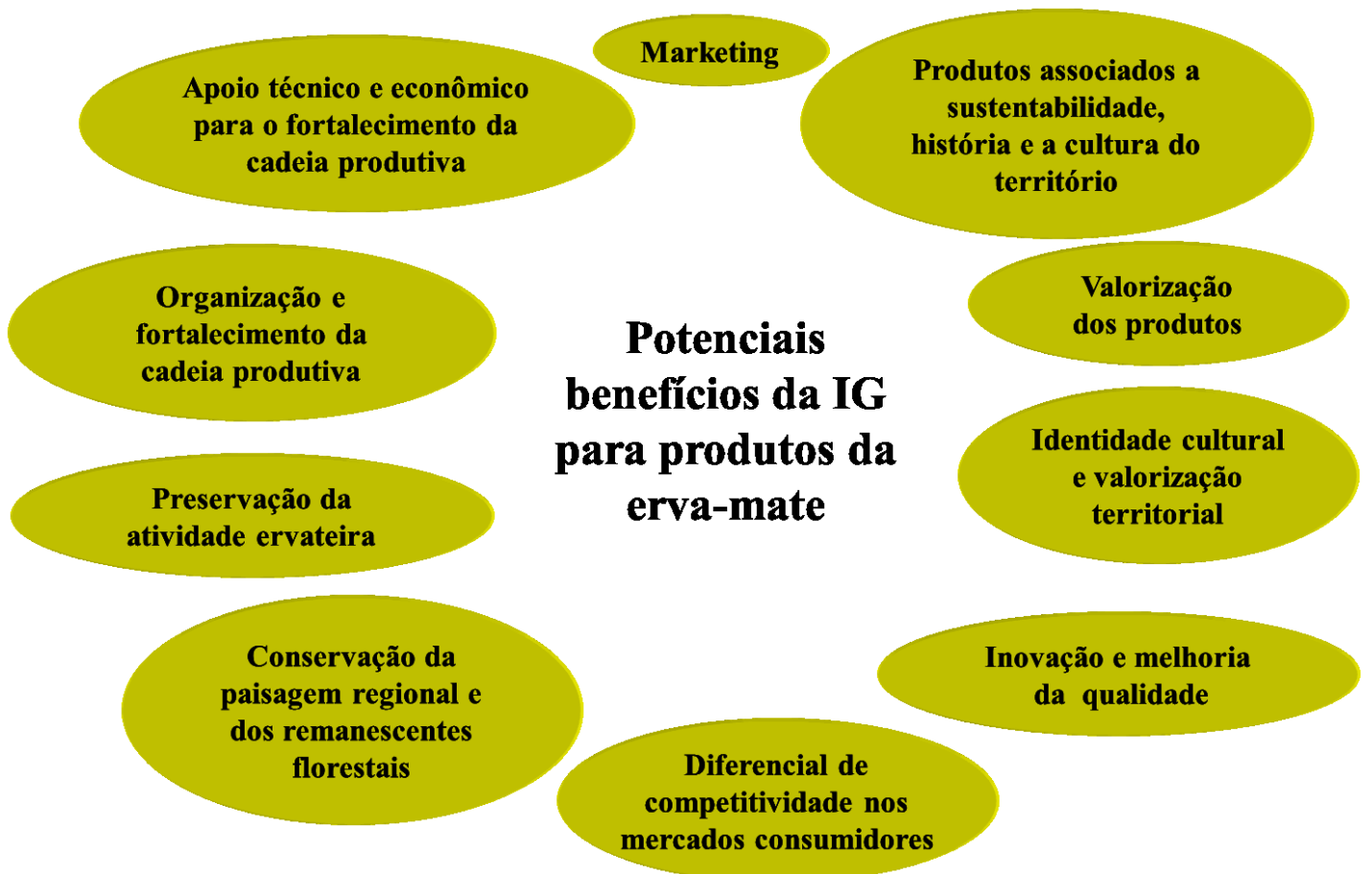

Fonte: Elaborado pelos autores com base em Pimentel e Silva (2013)

O Projeto "Ações para a promoção da Indicação Geográfica (IG) e a valorização do produto erva-mate no Planalto Norte Catarinense" busca em sua essência a participação dos atores da cadeia produtiva na sensibilização, na tomada de decisões, na viabilização de políticas públicas locais e territoriais, na participação em editais públicos, na resolução de gargalos estruturais e na construção de acordos coletivos em prol de um bem comum, como preconiza o guia do MAPA (2016).

Pretende com a promoção das ações sensibilizar agricultores ervateiros, processadores, distribuidores, técnicos, autoridades, agentes de desenvolvimento e demais atores da cadeia de valor da erva-mate, para o uso do signo distintivo da IG como estratégia para o desenvolvimento territorial. Além disso, o projeto prevê a realização de levantamento histórico-cultural da produção e transformação de erva-mate, a promoção da organização dos produtores em associação, a realização de pesquisas e estudos para subsidiar a delimitação da área geográfica e também para apoiar as discussões dos regulamentos e órgãos reguladores.

\section{CONTEXTUALIZAÇÃO HISTÓRICA DOS TRABALHOS}

A proposta de IG e produção orgânica para os produtos da erva-mate se deu de uma evolução de trabalhos em socioeconomia iniciados em uma das antecessoras da EPAGRI (ACARESC) em 1984, quando já se notava que a importância da atividade ervateira para a região era diferenciada em relação às outras regiões, pois tinha destaque na composição da 
margem bruta das propriedades estudadas, representando em média $8 \%$ da margem bruta das propriedades estudadas pelo programa (SOUZA, 1998c).

As bases do trabalho dão a possibilidade de estruturação do potencial de valorização para o território tradicional amplo que tem sua história profundamente ligada a esta atividade, com reputação e notoriedade reconhecida tanto no mercado interno como no mercado externo.

A primeira proposição para um projeto foi feita em 1999 em São Mateus do Sul-PR para técnicos e lideranças do setor, para estruturar um projeto territorial de IG, que incluísse o Sul e Centro Sul do Paraná.

Outras proposições foram feitas entre 1999 e 2003 em seminários e reuniões com apresentação da proposta. Em 1999 foi elaborado projeto de experimentação para o Fundo Nacional do Meio Ambiente, outro em arranjos florestais com predominância da erva-mate e de estudo dos ervais existentes no Planalto Norte Catarinense para subsidiar uma futura IG, mas ainda não tratando especificamente de sua constituição.

Em 2006, com a sinalização de apoio financeiro do Ministério da Agricultura (MAPA), teve a construção do primeiro esboço de projeto de IG.

Em 2007 com a realização da "Reunião para atualização técnica sobre produção e mercado de erva-mate, como alternativa de renda e conservação ambiental em sistemas de produção de agricultura familiar" teve avanço a proposta do projeto. $\mathrm{O}$ evento foi promovido por instituições ligadas à atividade ervateira nos estados e teve a participação da EPAGRI. O evento que ocorreu em São Mateus do Sul/PR produziu reflexos positivos na proposição de projetos conjuntos entre instituições do Planalto Norte Catarinense, especialmente o SINDIMATE, a Associação Ervateira Planalto Norte Catarinense, a EPAGRI, o Instituto Agronômico do Paraná (IAPAR), o Instituto Chico Mendes de Biodiversidade (ICMBio) e a ONG Ecoaraucária. 
Figura 7 - Linha do tempo com a contextualização histórica dos trabalhos das instituições quanto à valorização do produto erva-mate no Planalto Norte Catarinense

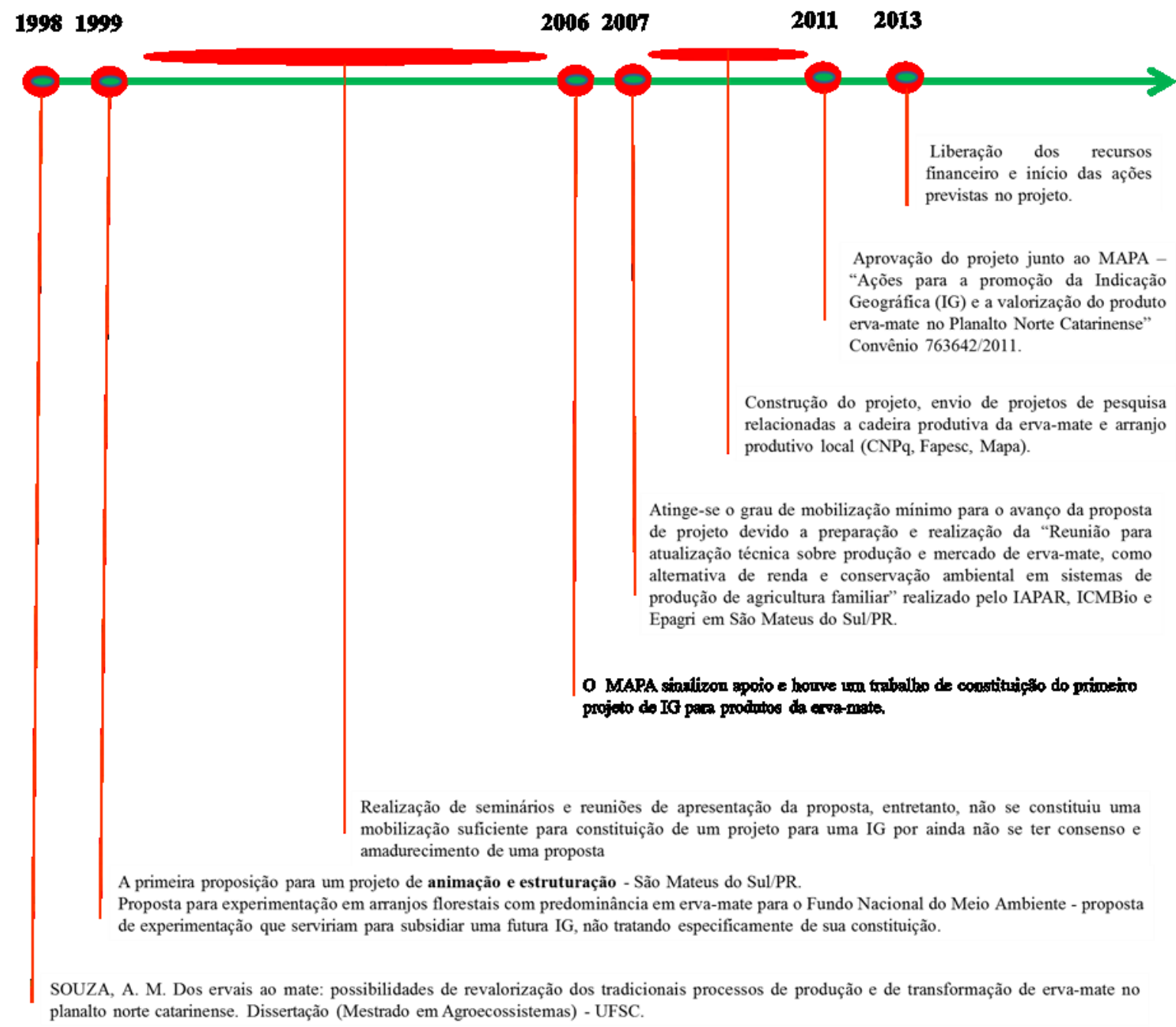

Fonte: Elaborado pelos autores (2016)

A EPAGRI, diante do quadro apresentado, visualizou a possibilidade de parceria e obtenção de recursos junto ao MAPA, sendo deflagrado processo de busca dessa parceria através do projeto denominado "Ações de apoio à estruturação da Indicação Geográfica Planalto Norte Catarinense para produtos da Erva-mate" que foi aprovado em 2011, que está em execução desde 2013.

O projeto foi financiado pelo MAPA pelo Convênio EPAGRI/MAPA 763642/2011 e se alicerça em ações de extensão, técnico-científicas e de resgate histórico (Figura 8).

O objetivo principal do projeto é promover todas as ações de apoio à estruturação e constituição da Indicação Geográfica (IG) Planalto Norte Catarinense para produtos da ervamate.

A metodologia tem foco na sensibilização dos atores da cadeia e das lideranças para a IG da erva-mate; nas ações de apoio às discussões de estatutos e regulamentações para a IG; 
nos estudos para as provas de reputação da IG; em pesquisas para delimitação do território da IG, para o manejo cultural e da transformação dos produtos da erva-mate.

Figura 8 - Cartaz de divulgação e promoção do projeto

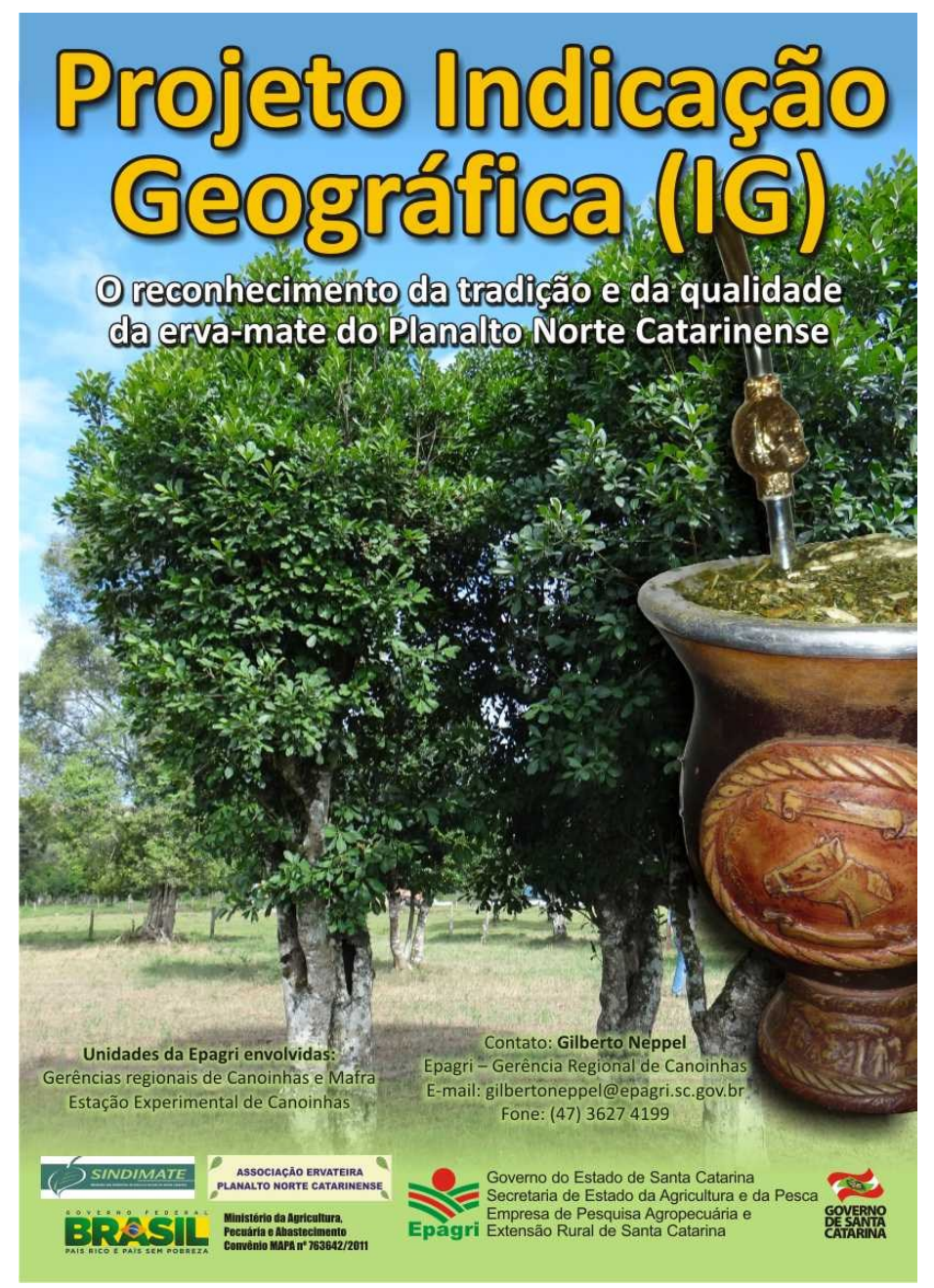

Fonte: Elaboração Epagri/GMC

Consequentemente, os resultados esperados são a sensibilização dos atores da cadeia erva-mate, sejam agricultores, processadores, distribuidores, técnicos, autoridades e agentes de desenvolvimento, para organizar e formar uma associação que constituirá a IG como estratégia para o desenvolvimento sustentável da região.

As ações previstas e em execução no projeto são as seguintes (Figura 9):

1. Sensibilizar os atores da cadeia produtiva, quais sejam, os agentes de desenvolvimento, lideranças, agricultores ervateiros e sociedade em geral, visando o fomento do projeto em todos os municípios da região;

2. Capacitar técnicos, agentes de desenvolvimento, industriais e agricultores ervateiros para os trabalhos da IG através da realização de viagens de intercâmbio à IG consolidadas e tradicionais; 
3. Iniciar a discussão dos estatutos e regulamentos da IG por meio de reuniões entre o grupo técnico;

4. Realizar estudos sobre informações históricas e provas de reputação/notoriedade para a IG;

5. Levantar e propor delimitação para a IG;

6. Pesquisar, estudar e difundir práticas de manejo utilizadas pelos agricultores para apoio à IG auxiliando e subsidiando a formatação preliminar de caderno de protocolos e regulamentos de uso da IG;

7. Realizar Seminário Estadual para promoção do projeto da IG.

Figura 9 - Fluxograma das metas do projeto "Ações de apoio à estruturação da Indicação Geográfica Planalto Norte Catarinense para produtos da Erva-mate" (Convênio Epagri/MAPA 763642/2011)

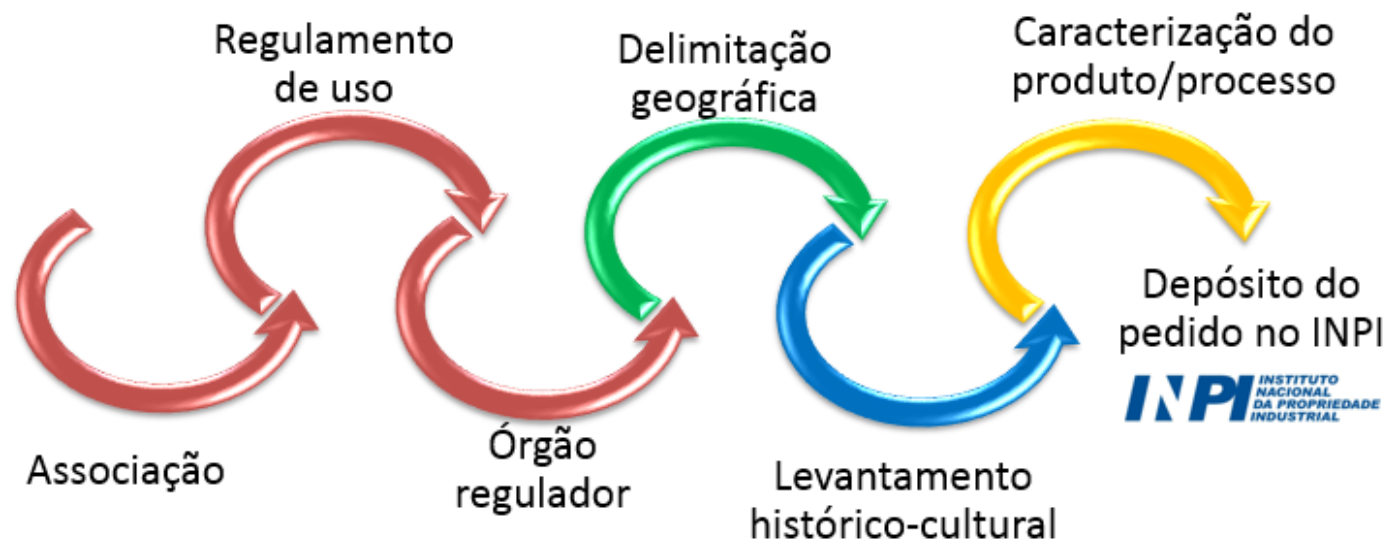

Fonte: Elaborado pelos autores com base nos requisitos para registro de uma IG junto ao INPI, (2016)

\section{PERSPECTIVAS E TRABALHOS FUTUROS}

Paralelamente, ações e pesquisas que as instituições desenvolvem ao longo dos anos e que já estão incorporados no dia-a-dia dos técnicos continuarão e se intensificarão para que ao final o projeto tenha os objetivos alcançados. A EPAGRI tem e pode seguir tendo um papel central na promoção, mas serão necessárias parcerias dentro de um quadro minimamente claro de responsabilidades para o alcance do objetivo maior que é a efetivação da IG. A construção de parcerias deverá ser suficientemente representativa dos diferentes atores existentes no território.

Os desafios para a efetivação da IG podem ser listados em quatro grandes grupos e etapas do trabalho:

1. A organização dos produtores e demais interessados no projeto: Ponto inicial e incontornável pois trata-se de projeto coletivo. Neste caso o objetivo individual e coletivo não pode ser diferente do objetivo da organização, que é o de defender e promover a IG; 
2. O levantamento histórico cultural: As provas de reputação são de grande riqueza e estão também vinculadas à delimitação a ser utilizada;

3. A delimitação da IG: Através de informações e elementos que comprovem que a região tem notoriedade para se tornar uma IG. É um ponto que vai além dos aspectos históricos da mais importante região ervateira brasileira, passa também pela necessidade de negociação e trabalho conjunto entre as entidades de Santa Catarina e do Paraná;

4. A caracterização do produto: Deve-se definir e listar os produtos a serem certificados, documentar cada etapa do processo de produção com o objetivo de garantir a tipicidade do produto.

Existe grande acúmulo de trabalho em todos os pontos acima, entretanto com o desenvolvimento do projeto já se projetam novos cenários para o futuro. Até o momento a realidade tem mostrado que é necessário muito trabalho, pesquisas, estudos, empenho, negociação, parcerias sólidas e interesses comuns para que este potencial se concretize.

\section{CONSIDERAÇÕES FINAIS}

A ligação histórica que o Planalto Norte de Santa Catarina mantém com a atividade ervateira e o diferencial de produção de erva-mate ligada aos processos de produção a partir dos ervais nativos demonstram que o potencial para ações para (re)valorização do produto regional, através de selos distintivos como: a Indicação Geográfica (IG), a produção e certificação orgânica ou outro selo com apelo socioambiental apresentam grande importância no desenvolvimento socioeconômico e ambiental do território.

A efetivação da IG para produtos da erva-mate através da comprovação da notoriedade, reputação e diferencial de qualidade buscam a valorização de um produto associado à sustentabilidade, a história e a cultura do território Planalto Norte Catarinense.

\section{REFERÊNCIAS}

ANDRADE, F. M. Exploração, manejo e potencial socioeconômico da erva-mate. In: SIMÕES, L. L.; LINO, F.C. Sustentável Mata Atlântica: a exploração de seus recursos florestais. Ed. SENAC/SP: São Paulo, 2002. p. 19-34.

CARVALHO, P. E. R. Espécies florestais brasileiras: recomendações silviculturais, potencialidades e uso da madeira: Empresa Brasileira de Pesquisa Agropecuária, Centro nacional de Pesquisas em Florestas. Colombo: EMBRAPA - CNPF, Brasília: EMBRAPA SPI, 1994. p. 281-287. 
CHAIMSOHN, F.P.; SOUZA, A.M. Sistemas de produção tradicionais e agroflorestais no Centro-Sul do Paraná e Norte Catarinense: Contribuições para a construção do processo de Indicação Geográfica. Ponta Grossa: Gráfica Planeta, 2013.

DA CROCE, D. M.; FLOSS, P. A. Cultura da erva-mate no Estado de Santa Catarina. Florianópolis - SC: Epagri, 1999. (Epagri. Boletim técnico, 100).

DA-RÉ, M. et al. Análise integrada das cadeias produtivas de espécies nativas da FOM e seu impacto sobre este ecossistema: relatório final: diagnóstico das cadeias produtivas do pinhão e da erva-mate, com análise da cadeia de valor e de impactos, normatização, políticas e efetividade e Benchmark, Certi: Florianópolis. 2012. v. 1. Disponível em:

$<\mathrm{http}$ ://www.fundacaogrupoboticario.org.br>. Acesso em: 12 set. 2013.

GERHARDT, M. História ambiental da erva-mate. Tese (Doutorado em História, Centro de Filosofia e Ciências Humanas da Universidade Federal de Santa Catarina), Florianópolis, 2013.

HOPPE M.; KNOPP E.; MEDRADO M. J. Erva-mate: diagnóstico e perspectivas de desenvolvimento. In: Erva-mate: diagnóstico e perspectivas de desenvolvimento. Venâncio Aires: Prefeitura Municipal, 1996, p. 7-22.

IBAMA. Portaria n. 118-N, de 12 de novembro de 1992. Dispõe sobre a classificação de produtos da erva-mate, tabela de conversão da erva-mate bruta para produto beneficiado e glossário de termos técnicos. Diário Oficial da União,13 de novembro de 1992, Seção I. Disponível em:<www.ibama.gov.br/flora/portarias/118_92.pdf>. Acesso em: 12 jan. 2016.

IBGE. Produção Agrícola Municipal - PAM. Disponível em:

$<$ http://www.ibge.gov.br/home/>. Acesso em: 17 jun. 2016 a.

IBGE. Produção da extração vegetal e da silvicultura - PEVS. Disponível em: $<$ http://www.ibge.gov.br/home/>. Acesso em: 17 jun. 2016 b.

INSTITUTO NCACIONAL DE LA YERBA MATE - INYM. Informe del sector yerbatero: marzo de 2016. Disponível em: <http://www.inym.org.ar>. Acesso em: 16 jun. 2016.

KLEIN, R. M. Árvores nativas da floresta subtropical do A Ito Uruguai. Sellowia, Itaja, v. 24, p. 17, 1972.

KLEIN, R.M. Árvores nativas da ilha de Santa Catarina. Insula, Florianópolis, v. 3, p. 12, 1969.

LOPES, N. O. V. E. A indicação geográfica como forma de valorização da biodiversidade no planalto norte catarinense. Dissertação (Mestrado em Agroecossistemas da Universidade Federal de Santa Catarina), Florianópolis, 2011.

MAPA Ministério da Agricultura, Pecuária e Abastecimento. Guia para solicitação de registro de indicação geográfica para produtos agropecuários. Disponível em $<$ http://www.agricultura.gov.br> Acesso em: 31 mar. 2016. 
MARQUES, A. C. As paisagens do mate e a conservação socioambiental: um estudo junto aos agricultores familiares do Planalto Norte Catarinense. Tese (Doutorado em Meio Ambiente e Desenvolvimento da Universidade Federal do Paraná), Curitiba, 2014.

MINISTÉRIO DE AGRICULTURA E GANADERÍA - MAG. Sintesis estadísticas: Produccion agrícola. Disponível em <http://www.mag.gov.py> Acesso em: 16 jun. 2016.

OLIVEIRA, Y. M. M.; ROTTA, E. Área de distribuição natural da erva-mate (Ilex paraguariensis St. Hil.). In: SEMINÁRIO SOBRE ATUALIDADES E PERSPECTIVAS FLORESTAIS. Silvicultura da erva-mate (Ilex paraguariensis St. Hil.), 1983, Curitiba: EMBRAPA CNPF, 1985. p. 17-36 (Documentos 15).

PIMENTEL, L. O. ; SILVA A. L. (Org.). Curso de propriedade intelectual \& inovação no agronegócio: Módulo II, Indicação Geográfica. Ministério da Agricultura, Pecuária e Abastecimento - Brasília; Florianópolis: EaD/UFSC, FUNJAB, 2013.

SIGNOR, P.; GOMES, G.S.; WATZLAWICK, L.F. Produção de erva-mate e conservação de Floresta com Araucária. Pesquisa Florestal Brasileira, Colombo, v.35, n. 83, p. 199-208, 2015.

SOUZA, A. M. Arranjo Produtivo Local e Indicação Geográfica: possibilidades para a Cadeia produtiva do "Mate" no Planalto Norte Catarinense. Sociedade Brasileira de Economia, Administração e Sociologia Rural (SOBER), Campo Grande, 2010.

SOUZA, A. M. Dos ervais ao mate: possibilidades de revalorização dos tradicionais processos de produção e de transformação de erva-mate no planalto norte catarinense. Dissertação (Mestrado em Agroecossistemas da Universidade Federal de Santa Catarina), Florianópolis, 1998a.

SOUZA, A. M. Dos ervais ao mate: cancheando números da atividade ervateira. In: SEMINÁRIO SOBRE MERCADO E TECNOLOGIA PARA OS SETORES DE BASE FLORESTAL, 2. ENCONTRO BRASILEIRO DE ENGENHEIROS FLORESTAIS, 10. FESTA DA ERVA-MATE, 1998, Canoinhas, Sc. Anais... Canoinhas, SC: Universidade do Contestado UnC, 1998b. p. 141-146.

SOUZA, A. M. Melhoria de ervais nativos presentes nos sistemas de produção do norte catarinense: o uso da poda alta em substituição a decepa baixa In: Encontro da Sociedade Brasileira de Sistemas de Produção, 1998, Florianópolis. Anais... Florianópolis, 1998c.

SOUZA, A.M. A estrutura fundiária do território Planalto Norte-SC: um produto das especificidades históricas. Sociedade Brasileira de Economia, Administração e Sociologia Rural (SOBER), Porto Alegre, 2009.

VALENTE, M.E.R. et al. Indicação geográfica de alimentos e bebidas no Brasil e na União Européia. Ciência Rural, Santa Maria, v.42, n. 3, p. 551-558, 2012.

VOGT, G. A. et al. Indicação geográfica (IG) e desenvolvimento territorial: situação e perspectivas da erva mate nas regiões Planalto Norte de Santa Catarina, Centro Sul e Sul do Paraná. In: DALLABRIDA, V. R. (Org.). Desenvolvimento territorial: políticas públicas 
brasileiras, experiências internacionais e a indicação geográfica como referência. São Paulo: LiberARs, 2014. p. 275-283.

Artigo recebido em: 21/06/2016

Artigo aprovado em: 11/07/2016 